\title{
Design Challenges for Social Interactions at Factory Floor
}

\author{
Milla Immonen \\ Smart Health, VTT Technical \\ Reseach Centre of Finland Ltd \\ Oulu, Finland \\ milla.immonen@vtt.fi
}

\author{
Paula Alavesa \\ Center for Ubiquitous Computing \\ University of Oulu \\ Oulu, Finland \\ paula.alavesa@oulu.fi
}

\author{
Vasiliki Mylonopoulou \\ M3 Research Unit \\ University of Oulu \\ Oulu, Finland \\ vasiliki.mylo@oulu.fi
}

\begin{abstract}
Industry 4.0, describes the transition of labor into more digitized and automated era. This transition makes it possible to develop a plethora of solutions for factory floor spanning from purely utilitarian to gamification. In this paper we present the initial step in recognizing the design challenges for a project developing social gamified eHealth applications to the factory floor.
\end{abstract}

Keywords-social interactions, scenario-based design, eHealth, factory floor, gamification

\section{INTRODUCTION}

In many western factories the current focus in health is in improving physical and mental health of the workers to facilitate longer careers and fewer sick days. This is made possible by the industry 4.0 movement and advances in eHealth [1]. Factories, however, pose challenging environment for games and applications with social emphasis due to the many context defined aspects, regulations and ethical considerations. There are some instances of gamification or serious games for manufacturing facilities $[3$, $4,5]$, but as a context for gamification is one of the least researched, whereas educational, health and well-being are the most popular area for gamification and serious games $[6,7$, 8].

Social interactions are a common element in designing gamified eHealth applications [2], whether they are interactions between the uses of healthcare professionals, the interactions have been found to be rewarding for the users. In the highly regulated work environment, it is difficult to say whether the benefits of facilitating social interactions can outweigh the potential dangers in compromised work security. Designing eHealth applications for the area where the products are made in a factory (factory floor) bring many opportunities, but also challenges in the form of heterogeneity of different tasks, workloads, different age groups, health status, genders, preferences and health literacy.
Previous solutions for gamification at factory floor have addressed improving the work satisfaction of the elderly and impaired. Korn et al. [3,5] do not address social interactions in their approach. Kampker et al. [9] created a learning game for automotive factory and their work resulted into a wider framework, they call four step model, for gamification at factories. Despite the light empirical validation, the framework is worth a mention as it does address the processes of socialization in work groups. They also mention a learning effect of increased communication between workers [9]. To our knowledge, designing specifically for social interactions has not been previously studied in this environment.

\section{DESIGN METHOD}

We used a design framework for social comparison by Mylonopoulou et al. [10] to recognize the challenging aspects of designing for social interactions. We created a persona based on our knowledge of factory workers at a manufacturing facility [anonymized] during a workshop and consecutively created two different age personas to complement the fact that the factory workers present somewhat heterogeneous demographics age wise. While it is not sure if age affects their willingness to change towards healthier behavior $[11,13]$ it does influence the prime health concerns [14]. This divided out personas to three age groups: young, middle-aged and aging. Our understanding of the factory workers comes from series of interviews conducted on site during 2018-2019, but this work in progress -paper present a scenario-based design in progress on the solutions for social issues in gamified eHealth for factory floor. The personas created for the discussion can be found in Table I. The readiness to change presents the persons' awareness of their condition and willingness to change. Although Mylonopoulou et al.'s [10] framework specifically targets social comparison it is applicable for evaluating the social interactions in challenging conditions as it addresses the sensitive context of health applications and it is based on social comparison theory [12]. Here however we step outside the original framework and adapt the guidelines for designing for social interactions. The

TABLE I. PERSONAS CREATED FOR THE SCENARIO IDEATION

\begin{tabular}{|c|c|c|c|c|}
\hline Persona* & $\begin{array}{c}\text { Work } \\
\text { Experience } \\
\text { (y) }\end{array}$ & Description & Proposed Solution & $\begin{array}{l}\text { Readiness } \\
\text { to change }\end{array}$ \\
\hline Young, 22 & 1 & $\begin{array}{l}\text { Does not yet have health problems besides some } \\
\text { mental load about worrying on job security }\end{array}$ & $\begin{array}{l}\text { Social interactions involving the young for self } \\
\text { evaluation and prediction. }\end{array}$ & Low \\
\hline $\begin{array}{l}\text { Middle- } \\
\text { aged, } 38\end{array}$ & 10 & $\begin{array}{l}\text { Is becoming concerned of her healt and work life } \\
\text { balance. She knows she should take brakes while } \\
\text { working, but is too engaged with work. She is afraid } \\
\text { harming the collaborative work flow if she steps back } \\
\text { from the line. }\end{array}$ & $\begin{array}{l}\text { Social interactions by joined notifications for the } \\
\text { breaks and increased communication with others. }\end{array}$ & $\begin{array}{l}\text { Slightly } \\
\text { Increased }\end{array}$ \\
\hline Aging, 53 & 30 & $\begin{array}{l}\text { Already has health issues related to sleep patterns and } \\
\text { diet. Would benefit from eHealth intervention, but } \\
\text { feels suspicious about it. }\end{array}$ & $\begin{array}{l}\text { Social ineractions for increased empathy and } \\
\text { guidance from fellow workers in using digital } \\
\text { interventions. }\end{array}$ & High \\
\hline
\end{tabular}

\footnotetext{
*the details do not present any actual person from the factory, but represent the personas created for the workshop
} 
original framework states that comparison needs to be targeted at peers, whereas we explore in this design the possibilities of facilitating interactions across the different age groups of people with varying needs for eHealth interventions.

\section{DISCUSSION AND CONCLUSIONS}

In addition to challenges there are some benefits facilitating social interactions can provide. The need for change is higher for aging factory workers, but they may have difficulties with digital interventions [13]. Here social interaction can aid by providing a channel for guidance as also described by Kampker et al. [9]. The lateral transparency brought on by social interactions can also create empathy amongst workers, but the interaction must be tailored so that the privacy of the participants is respected. Privacy and data security are one of the key challenges for eHealth solutions for other contexts as well [15]. These issues however need to be addressed before the eHealth solutions evoke users' trust. Monitoring workers for various purposes and motivations is currently increasing, enough to evoke public debate [16]. How the collected monitoring data is used is topical issue in the industry 4.0 [1]. Involving the workers in decision making and design on systems, such as eHealth applications, can also address this issue.

It is possible that the slightly optimistic benefits for social interactions are overweighed by the challenges. At the same time, we cannot yet present definitive solutions for these challenges. One solution could be considered transparency and openness of data collection methods in addition to involving the workers themselves into the process of developing the solutions. The solutions cannot be forced upon the workers but taking their sensitivities into consideration can improve the acceptance rates. Based on our preliminary assessment we cannot recommend designing gamification, with social interactions for factory floor, without good understanding of the context related issues. This requires user involvement in the process.

\section{A. Limitations and Future Work}

In this paper we present what is clearly a work in progress in designing eHealth solutions for highly digitalized European and specifically Finnish factories, which are somewhat regulated according to the same directives. This restricts the generalizability of our findings.

In the future we plan to extend this study to other collaborating factories in our current project. We plan to design, implement and deploy different eHealth solutions into these factories. These steps will further out research, improve generalizability and provide us material for creating design guidelines for eHealth applications and solutions for factory floor. This study has been conducted according to the local ethical guidelines of University of Oulu, Finland. We in addition are working, in the same project for joined GDPR and labour law compatible guidelines for data collection at workplace.

While we are, for the future work, looking into other frameworks for designing for social interactions. We are also keen on finding ways of validating this framework [10] to be used in any design context, where there are specific challenges regulating and restricting what can be shared between users.

\section{ACKNOWLEDGMENTS}

This research is done in a Business Finland funded project Reboot Finland IoT Factory 33/31/2018 supported by Academy of Finland 6Genesis Flagship (318927).

\section{REFERENCES}

[1] M. Alloghani, D. Al-Jumeily, A. Hussain, A. J. Aljaaf, J. Mustafina, and E. Petrov, "Healthcare Services Innovations based on the state of the art Technology Trend Industry 4.0," in 2018 11th International Conference on Developments in eSystems Engineering (DeSE), 2018, pp. 64-70.

[2] L. Sardi, A. Idri, and J. L. Fernández-Alemán, "A systematic review of gamification in e-Health," Journal of biomedical informatics, vol. 71, pp. 31-48, 2017.

[3] O. Korn, M. Funk, and A. Schmidt, "Design approaches for the gamification of production environments: a study focusing on acceptance," in Proceedings of the 8th ACM International Conference on PErvasive Technologies Related to Assistive Environments, 2015, p. 6.

[4] A. Kampker, C. Deutskens, K. Deutschmann, A. Maue, and A. Haunreiter, "Increasing Ramp-up Performance By Implementing the Gamification Approach," Procedia CIRP, vol. 20, pp. 74-80, 2014.

[5] O. Korn, "Industrial playgrounds: how gamification helps to enrich work for elderly or impaired persons in production," in Proceedings of the 4th ACM SIGCHI symposium on Engineering interactive computing systems, 2012, pp. 313-316.

[6] G. Barata, S. Gama, J. Jorge, and D. Gonçalves, "Studying student differentiation in gamified education: A long-term study," Computers in Human Behavior, vol. 71, pp. 550-585, 2017.

[7] J. Hamari, J. Koivisto, and H. Sarsa, "Does gamification work?--a literature review of empirical studies on gamification," in 2014 47th Hawaii international conference on system sciences (HICSS), 2014, pp. 3025-3034.

[8] R. A. Ratan and U. Ritterfeld, "Classifying serious games," in Serious games, Routledge, 2009, pp. 32-46.

[9] A. Kampker, C. Deutskens, K. Deutschmann, A. Maue, and A. Haunreiter, "Increasing Ramp-up Performance By Implementing the Gamification Approach," Procedia CIRP, vol. 20, pp. 74-80, 2014.

[10] V. Mylonopoulou, M. Isomursu, and K. Vayrynen, "Designing for Well-being and Healthcare Using Social Comparison," in Proceedings of the 22nd International Academic Mindtrek Conference, Tampere, Finland, 2018, pp. 266-269.

[11] P. Kummervold et al., "eHealth trends in Europe 2005-2007: a population-based survey," Journal of medical Internet research, vol. 10, no. 4, p. e42, 2008.

[12] L. Festinger, "A theory of social comparison processes," Human relations, vol. 7, no. 2, pp. 117-140, 1954.

[13] S. O'Connor, P. Hanlon, C. A. O'Donnell, S. Garcia, J. Glanville, and F. S. Mair, "Understanding factors affecting patient and public engagement and recruitment to digital health interventions: a systematic review of qualitative studies," BMC Medical Informatics and Decision Making, vol. 16, no. 1, p. 120, Sep. 2016.

[14] M. Kivimäki, P. Leino-Arjas, R. Luukkonen, H. Riihimäi, J. Vahtera, and J. Kirjonen, "Work stress and risk of cardiovascular mortality: prospective cohort study of industrial employees," $B m j$, vol. 325, no. 7369 , p. 857, 2002.

[15] N. Dong, H. Jonker, and J. Pang, "Challenges in ehealth: From enabling to enforcing privacy," in International Symposium on Foundations of Health Informatics Engineering and Systems, 2011, pp. 195-206.

[16] P. Belton, "How does it feel to be watched at work all the time?," 12Apr-2019. 